\title{
A FIXAÇÃO DO QUANTUM DEBEATUR NAS AÇÕES INDENIZATÓRIAS AMBIENTAIS
}

\section{Elcio Nacur Rezende}

Mestre e Doutor em Direito. Professor do Programa de Pós-graduação da Escola Superior Dom Helder Câmara. E-mail: elcionrezende@yahoo.com.br.

\section{Nivaldo Caetano da Cunha}

Engenheiro Florestal. Analista do Ministério Público do Estado de Minas Gerais. Mestrando em Direito Ambiental e Desenvolvimento Sustentável da Escola Superior Dom Helder Câmara. E-mail: nicclaudo@yahoo.com.br.

Resumo: Este artigo tem por objetivo dissertar sobre a fixação do quantum debeatur nas ações indenizatórias ambientais, haja vista as dificuldades existentes para os aplicadores do Direito quando se faz necessária a utilização da indenização na esfera da reparação ambiental, princípio da disciplina Direito Ambiental que hoje goza de status constitucional. O método de abordagem utilizado foi o indutivo, através da pesquisa bibliográfica, selecionando e mencionando diferentes posições doutrinárias sobre o tema. Há uma incerteza jurídica que permeia a matéria. Essa incerteza jurídica é fruto das características do dano ambiental e das diversas formas de reparação ambiental, que exigem trabalhos transdisciplinares entre os profissionais do Direito e os profissionais de outras disciplinas para tornar efetivo o direito ao meio ambiente ecologicamente equilibrado.

Palavras-chave: Responsabilidade civil ambiental. Dano ambiental. Reparação ambiental. Indenização ambiental.

Sumário: 1 Introdução - $\mathbf{2}$ Da responsabilidade civil por danos ao meio ambiente - $\mathbf{3}$ Da reparação do dano ambiental - $\mathbf{4}$ A fixação do quantum debeatur nas ações indenizatórias ambientais - $\mathbf{5}$ Conclusão - Referências

\section{Introdução}

As atitudes ou omissões das pessoas geram consequências positivas ou negativas para si mesmas ou para outrem. A lei cunhada pelo físico inglês Isaac Newton no século XVII e que confirma tal assertiva é que "para toda ação há sempre uma reação oposta e de igual intensidade".

A lei, também conhecida como o Princípio da Ação e Reação, foi elaborada pelo físico ao pensar na interação entre dois corpos ou objetos sólidos, concretos. As abstrações não são consideradas nessa lei, quando se estuda os fenômenos contemplados na ciência Física. 
Essa lei, através dos tempos, vem se tornando um adágio. Com isso, extrapola os limites da ciência Física para ser utilizada em outras áreas que dizem respeito à conduta humana. A intenção, nesse caso, é dizer aos seres humanos que é preciso ponderar, pensar, antes de se tomar qualquer decisão, pois, ao agir ou se omitir, consequências advirão em virtude da decisão tomada.

Quando as consequências ou os resultados da decisão tomada são negativos para outras pessoas, há que se responder por elas. Nesse sentido, o Princípio da Ação e Reação entra na seara da abstração. Nesse caso, os resultados alcançados com as decisões tomadas não se restringem somente àquilo que diz respeito ao concreto, material ou imediatamente mensurável, mas também ao que diz respeito às emoções, aos sentimentos negativos causados em outrem pelas decisões previamente tomadas.

A resposta ou ressarcimento a serem dados nesses casos podem ser analisados tanto no campo da Moral quanto no campo do Direito. Uma análise difere da outra com base no princípio da coerção, característica essa do Direito. Significa dizer que, enquanto na esfera da Moral, é o próprio sujeito que determina a sua conduta, de maneira a não prejudicar outras pessoas em suas relações; na esfera do Direito, é a lei que impõe a conduta do indivíduo quanto a esse mister.

Quanto à diferença entre Moral e Direito, assim pontua Miguel Reale (2001, p. 43):

O cumprimento obrigatório da sentença satisfaz ao mundo jurídico, mas continua alheio ao campo propriamente moral. Isto nos demonstra que existe, entre o Direito e a Moral, uma diferença básica, que podemos indicar com esta expressão: a Moral é incoercível e o Direito é coercível. O que distingue o Direito da Moral, portanto, é a coercibilidade. Coercibilidade é uma expressão técnica que serve para mostrar a plena compatibilidade que existe entre o Direito e a força (grifo do autor).

O princípio da responsabilização surge da obrigação de se responder pelas consequências negativas advindas da conduta humana. As sanções são definidas juridicamente dentro da esfera penal, administrativa e civil.

Essa tríplice responsabilização é também observada nas questões que versam sobre o meio ambiente. Neste artigo, a dissertação é sobre a responsabilidade civil ambiental. O objetivo é focar na fixação do quantum debeatur nas ações indenizatórias ambientais, haja vista ser a indenização um dos princípios que compõem a responsabilidade civil.

Infringida a lei, surge a lesão a direitos e, por consequência, a necessidade de resposta ou a obrigação de reparar a lesão ou o dano causado. É desses aspectos 
jurídicos que trata o instituto da responsabilidade civil, ou seja, da obrigação de reparar os danos causados a outrem em decorrência da conduta humana que infringe os dispositivos legais.

\section{Da responsabilidade civil por danos ao meio ambiente}

A relação cognata entre a palavra responsabilização e o verbo responder é clara. São termos etimologicamente originários de uma mesma raiz. Leite e Ayala (2011, p. 121) citam Custódio (1983, p. 16) e De Plácido e Silva (1982, p. $124-$ 125) para esclarecerem que "a palavra responsabilidade deriva etimologicamente de responsável, que se origina do latim responsus, do verbo respondere (responder, afiançar, prometer, pagar), que transmite a ideia de reparar, recuperar, compensar, ou pagar pelo que fez" (grifo dos autores).

A Constituição da República Federativa do Brasil de 1988 acolheu a responsabilização tríplice sobre o causador de danos ambientais ao inserir no parágrafo 3o do artigo 225 os seguintes dizeres: "As condutas e atividades consideradas lesivas ao meio ambiente sujeitarão os infratores, pessoas físicas ou jurídicas, a sanções penais e administrativas, independentemente da obrigação de reparar os danos causados".

Observa-se, na análise do dispositivo constitucional, que as sanções serão penais e administrativas, devendo vir acrescidas da obrigação de reparar os danos causados. A independência mencionada no dispositivo deixa claro que as sanções podem ser aplicadas em separado ou cumulativamente. Ressalta-se na expressão "obrigação de reparar os danos causados" a característica básica da responsabilidade civil, pois esta se encarrega exatamente da reparação dos danos originários da conduta humana.

Em análise ao Direito Ambiental, Paulo Affonso Leme Machado (2006, p. 349) argumenta que "o Direito Ambiental apresenta um novo tipo de comportamento ao efetivar-se a responsabilização jurídica do poluidor ou do agressor dos recursos naturais".

Em matéria ambiental, o objeto danificado é o meio ambiente e o sujeito prejudicado é a coletividade. 0 artigo 225 da Constituição Federal do Brasil de 1988, caput, esclarece essa situação ao afirmar que "todos têm direito ao meio ambiente ecologicamente equilibrado, bem de uso comum do povo e essencial à sadia qualidade de vida, $[\ldots] "$.

A lesão ao direito de toda a coletividade ocorre quando as condutas e atividades afetam o meio ambiente, desequilibrando-o em qualquer um de seus componentes, que, por interagir com outros elementos do meio ambiente, muitas das vezes dificultam mensurar a amplitude do dano causado. 
Quando se diz que a Constituição Federal do Brasil de 1988 acolheu a responsabilização tríplice sobre o causador de danos ao meio ambiente é porque a Lei no 6.938, de 31 de agosto de 1981 (Brasil, 1981), que dispõe sobre a Política Nacional do Meio Ambiente - PNMA, já disciplinava a matéria. Uma leitura mais atenciosa dessa lei demonstra que em sua elaboração o legislador federal deixou clara, ainda que resumidamente, a responsabilização tríplice por danos ao meio ambiente.

O artigo 14 da Lei da PNMA, em seus incisos I, II, III e IV, trata da responsabilidade administrativa ao determinar o que segue:

Art. 14 Sem prejuízo das penalidades definidas pela legislação federal, estadual e municipal, o não cumprimento das medidas necessárias à preservação ou correção dos inconvenientes e danos causados pela degradação da qualidade ambiental sujeitará os transgressores: I - à multa simples ou diária, nos valores correspondentes, no mínimo, a 10 (dez) e, no máximo, a 1.000 (mil) Obrigações Reajustáveis do Tesouro Nacional - ORTNs, agravada em casos de reincidência específica, conforme dispuser o regulamento, vedada a sua cobrança pela União se já tiver sido aplicada pelo Estado, Distrito Federal, Territórios ou pelos Municípios.

II - à perda ou restrição de incentivos e benefícios fiscais concedidos pelo Poder Público;

III - à perda ou suspensão de participação em linhas de financiamento em estabelecimentos oficiais de crédito;

IV - à suspensão de sua atividade.

Por sua vez, o artigo 15 da Lei no 6.938/81 (Brasil, 1981) trata da responsabilidade penal com os seguintes dizeres:

Artigo 150 poluidor que expuser a perigo a incolumidade humana, animal ou vegetal, ou estiver tornando mais grave situação de perigo existente, fica sujeito a pena de reclusão de 1 (um) a 3 (três) anos e multa de 100 (cem) a 1.000 (mil) MVR.

$\S 1$ - A pena e aumentada até o dobro se:

I - resultar:

a) dano irreversível a fauna, a flora e ao meio ambiente;

b) lesão corporal grave;

II - a poluição e decorrente de atividade industrial ou de transporte;

III - o crime e praticado durante a noite, em domingo ou em feriado. 
§2ำ - Incorre no mesmo crime a autoridade competente que deixar de promover as medidas tendentes a impedir a prática das condutas acima descritas.

Quanto à responsabilidade civil por danos ao meio ambiente, matéria do interesse destes escritos, observa-se, de imediato, ser tratada como um dos objetivos da Política Nacional do Meio Ambiente, consoante o artigo 4ํㅡ, VII, da Lei ํㅜ 6.938/81 (Brasil, 1981):

Art. 4ํA Política Nacional do Meio Ambiente visará:

$[\ldots]$

VII - a imposição, ao poluidor e ao predador, da obrigação de recuperar e/ou indenizar os danos causados e, ao usuário, da contribuição pela utilização de recursos ambientais com fins econômicos.

De tal dispositivo jurídico há de se chamar a atenção para o fato de a Lei da PNMA mencionar como obrigações impostas ao poluidor e ao predador a recuperação ou a indenização aplicadas, reitera-se, separadamente ou de maneira cumulativa. Isto porque, em algumas situações de ocorrência do dano ambiental, somente a aplicação de uma das maneiras de reparar não será suficiente para compensar o prejuízo causado ao meio ambiente por atividades antrópicas que o danifiquem.

As características do dano ambiental condicionam a aplicação de mais de uma das formas de repará-lo. A dificuldade de se mensurar a abrangência do dano ambiental constitui uma das características que justifica a aplicação da recuperação ambiental, acrescida da indenização. A abrangência diz respeito à dispersão espacial e ao número de vítimas - elementos naturais e pessoas - atingidas.

Além da dificuldade de se mensurar a abrangência, a dificuldade para se reparar e/ou valorar monetariamente o dano ambiental deve ser também considerada na análise das questões ambientais.

Mirra (2004, p. 90), ao definir e caracterizar o dano ambiental, leciona que

O dano ambiental, segundo entendemos, consiste na lesão ao meio ambiente, abrangente dos elementos naturais, artificiais e culturais, como bem de uso comum do povo, juridicamente protegido. Significa, ainda, a violação do direito de todos ao meio ambiente ecologicamente equilibrado, direito humano fundamental, de natureza difusa.

$[\ldots]$

Nesses termos, é importante observar que os danos ao meio ambiente manifestam-se normalmente, em um primeiro plano, que se 
poderia dizer mais ostensivo e perceptível, nas agressões aos bens ambientais corpóreos e incorpóreos, como se dá com as poluições das águas continentais e oceânicas, do ar e dos solos; com a destruição da fauna e da flora; com a erosão e suas consequências sobre os solos, a vegetação, a fauna nela enfeudada e os cursos d'água; com a degradação dos ecossistemas terrestres e aquáticos e dos processos ecológicos a eles relacionados; com a destruição de bens e valores integrantes do patrimônio histórico, artístico, estético, arquitetônico e paisagístico; com os atentados a praças e espaços de lazer etc.

Tendo por base o conceito de meio ambiente trazido à luz pela Lei oㅜ 6.938, de 31 de agosto de 1981 (Brasil, 1981) (Dispõe sobre a Política Nacional do Meio Ambiente, seus fins e mecanismos de formulação e aplicação, e dá outras providências), artigo 3o, I, onde se lê que o “meio ambiente é o conjunto de condições, leis, influências e interações de ordem física, química e biológica, que permite, abriga e rege a vida em todas as suas formas", Mirra (2004, p. 94) acrescenta:

Portanto, ao nosso ver, em vista do exposto, o dano ambiental pode ser definido como toda degradação do meio ambiente, incluindo os aspectos naturais, culturais e artificiais que permitem e condicionam a vida, visto como bem unitário, imaterial coletivo e indivisivel, e dos bens ambientais e seus elementos corpóreos e incorpóreos específicos que o compõem, caracterizadora da violação do direito difuso e fundamental de todos à sadia qualidade de vida em um ambiente são e ecologicamente equilibrado (grifo do autor).

A responsabilidade civil por danos ao meio ambiente, além de gozar do status de ser um dos objetivos da Política Nacional do Meio Ambiente, é enfatizada no artigo 14 da Lei no 6.938/81 (Brasil, 81), que, ao tratar das penalidades referentes à responsabilidade administrativa, salienta no parágrafo 1을

Artigo 14 Sem prejuízo das penalidades definidas pela legislação federal, estadual e municipal, o não cumprimento das medidas necessárias à preservação ou correção dos inconvenientes e danos causados pela degradação da qualidade ambiental sujeitara os transgressores:

[...]

$\S 1^{\circ}$ - Sem obstar a aplicação das penalidades previstas neste artigo, é o poluidor obrigado, independentemente da existência de culpa, a indenizar ou reparar os danos causados ao meio ambiente e a terceiros, 
afetados por sua atividade. O Ministério Público da União e dos Estados terá legitimidade para propor ação de responsabilidade civil e criminal, por danos causados ao meio ambiente (grifo nosso).

Ao dizer que a obrigação de indenizar ou reparar os danos causados ao meio ambiente independe da existência de culpa, a Lei estabelece que a responsabilidade civil por dano ao meio ambiente é objetiva, em detrimento da responsabilidade civil subjetiva. A responsabilidade civil subjetiva constitui a regra e responsabilidade civil objetiva a exceção, no ordenamento jurídico brasileiro.

Em se tratando da responsabilidade civil subjetiva, para que surja o dever de indenizar ou reparar, quatro elementos precisam estar evidentes, quais sejam: conduta humana (ação ou omissão), nexo causal, dano e a culpa, com grande ênfase nesse último elemento.

Rodrigues (2002, p. 11), quanto à responsabilidade subjetiva, esclarece que

[...] se diz ser subjetiva a responsabilidade quando se inspira na ideia de culpa e que de acordo com o entendimento clássico a concepção tradicional a responsabilidade do agente causador do dano só se configura se agiu culposa ou dolosamente. De modo que a prova da culpa do agente causador do dano é indispensável para que surja o dever de indenizar. A responsabilidade, no caso, é subjetiva, pois depende do comportamento do sujeito.

$\mathrm{Na}$ aplicação da responsabilidade civil objetiva, o elemento culpa, dentre os quatro antes enumerados, não se faz necessário para a análise da obrigação de indenizar ou reparar, conforme dispõe o parágrafo 1ํㅡ do artigo 14 da Lei no 6.938/81 (Brasil, 81).

Da lição de Rodrigues (2002, p. 10) extrai-se o resumo sobre a responsabilidade objetiva:

Na responsabilidade objetiva a atitude culposa ou dolosa do agente causador do dano é de menor relevância, pois, desde que exista relação de causalidade entre o dano experimentado pela vítima e o ato do agente, surge o dever de indenizar, quer tenha este último agido ou não culposamente.

Vladimir Passos de Freitas (2001, p. 26), ao dissertar sobre a responsabilidade objetiva, lança mão da Lei no 9.605 de 1998 - que dispõe sobre as sanções penais e administrativas derivadas de condutas e atividades lesivas ao meio ambiente e dá outras providências - em consonância com o Decreto no 3.179, de 21 
de setembro de 1999, esse revogado pelo Decreto n 6.514 , de 22 de julho de 2008 - que dispõe sobre as infrações e sanções administrativas ao meio ambiente, estabelece o processo administrativo federal para apuração destas infrações e dá outras providências. Relata o autor:

Já o art. 2º $§ 10$, do Regulamento, Decreto 3.179/99, de 21.09.99 determina que o infrator é obrigado a reparar o dano independentemente da existência de culpa. É dizer, a responsabilidade é objetiva e o dever de recuperar o meio ambiente decorre da simples prova de prejuízo.

Esta foi a intenção do legislador, pois a Lei 9.605 de 1998, em momento algum faz a distinção excluindo a responsabilidade de quem se houve com culpa. Aliás, há casos em que a mera omissão já é o suficiente para configurar infração.

A análise é feita com base somente nos três elementos que antecedem a culpa, ou seja, conduta humana (ação ou omissão), nexo causal e dano.

Cavalieri Filho (2008, p. 145) deixa claro que

[...] Se fosse possível invocar o caso fortuito ou a força maior [ou ainda a culpa exclusiva da vítima e fato de terceiro] como causas excludentes da responsabilidade civil por dano ecológico, ficaria fora da incidência da lei, a maior parte dos casos de poluição ambiental, como a destruição da fauna e da flora causada por carga tóxica de navios avariados em tempestades marítimas; rompimento de oleoduto em circunstâncias absolutamente imprevisiveis, poluindo lagoas, baías, praias e mar; contaminação de estradas e rios, atingindo vários municípios, provocada por acidentes imponderáveis de grandes veículos transportadores de material poluente e assim por diante.

A Constituição da República Federativa do Brasil de 1988 e a Lei no 6.938/81 afirmam que os autores das atividades antrópicas que causam danos ao meio ambiente respondem nas esferas civil, penal e administrativa. 0 interesse principal destes escritos é a reparação do dano ambiental, competência da esfera civil.

\section{Da reparação do dano ambiental}

Neste momento, faz-se necessário verificar os pontos comuns e divergentes entre o objetivo da responsabilidade civil considerada em sentido genérico e o objetivo da responsabilidade civil por danos ao meio ambiente. Salienta-se que, 
enquanto aquela tem por objetivo a reposição completa da vítima à situação anterior à lesão, esta, por sua vez, tem por objetivo a reparação dos bens ambientais lesados, em detrimento da vítima.

Segundo Lopes (2011, p. 1), quando se trata da responsabilidade civil em sentido genérico:

É objetivo da responsabilidade civil, restituir o dano por completo, sendo hoje dominante o principio da restitutio in integrum, ou seja, a reposição completa da vitima a situação anterior à lesão, por meio de uma reconstituição natural, buscando uma situação material correspondente ou por uma indenização mais próxima possível do valor do prejuízo (grifo do autor).

Por sua vez, Cardin e Barbosa (2008, p. 159), ao tratarem da responsabilidade civil por danos ao meio ambiente, comparativamente lecionam que

Uma vez ocorrido o dano ao meio ambiente, a principal opção não vai ser o ressarcimento da vítima, mas a reconstituição, recomposição e reintegração dos bens ambientais lesados. O sentido é de reconstituição da integridade e funcionalidade do objeto. A prioridade do sistema de reparação é a restauração natural, isto é, busca-se o retorno ao status quo ante do meio ambiente (grifo dos autores).

Adiante os autores salientam que "entre a possibilidade da aplicação da restauração natural e da indenização pecuniária, a preferência fica com a restauração natural, por ser mais vantajosa ao meio ambiente" (CARDIN; BARBOSA, 2008, p. 160).

Ao tratar do princípio da reparação ambiental, a legislação usa termos que guardam entre si uma relação semântica, sinonímica, sem, no entanto, terem o mesmo significado. Assim, é possível verificar, por exemplo, o uso dos verbos reparar, recuperar, recompor, reconstituir e reintegrar como sinônimos.

$\mathrm{Na}$ Constituição da República Federativa do Brasil de 1988, o legislador constituinte usou os termos reparar e recuperar no artigo 225 em parágrafos que se seguem - 2ำ e $3^{\circ}$ - provavelmente para expressar a mesma coisa em ambas as situações, conforme segue:

$\S 2^{\circ}$ Aquele que explorar recursos minerais fica obrigado a recuperar o meio ambiente degradado, de acordo com solução técnica exigida pelo órgão público competente, na forma da lei.

$\S 3^{\circ}$ As condutas e atividades consideradas lesivas ao meio ambiente sujeitarão os infratores, pessoas físicas ou jurídicas, a sanções penais 
e administrativas, independentemente da obrigação de reparar os danos causados (grifo nosso).

Freitas (2011, p. 13), com propriedade, pergunta: “há necessidade de distingui-los para os fins da tutela ambiental"? Tendo por base a Lei no 9.985/200 (Brasil, 2000), que regulamenta o artigo 225, §1ำ, incisos I, II, III e VII, da Constituição Federal, e institui o Sistema Nacional de Unidades de Conservação da Natureza (SNUC), a autora leciona que "deve ficar claro que há gradação entre tais modalidades de reparação do dano ambiental: primeiro se busca a restauração; caso esta não seja possível, parte-se para a recuperação" (FREITAS, 2011, p. 14).

A Lei no 9.985/200 (Brasil, 2000) assim define os dois termos - recuperação e restauração - no artigo $2^{\circ}$, XII e XIV:

Art. $2{ }^{\circ}$ Para os fins previstos nesta Lei, entende-se por:

XIII - recuperação: restituição de um ecossistema ou de uma população silvestre degradada a uma condição não degradada, que pode ser diferente de sua condição original.

XIV - restauração: restituição de um ecossistema ou de uma população silvestre degradada o mais próximo possivel da sua condição original (grifo nosso).

A preocupação com a condição original do ecossistema ou população silvestre degradada distingue os dois termos, deixando clara a prevalência da restauração sobre a recuperação por demonstrar na sua aplicação a necessidade de se buscar a originalidade antes degradada.

Com isso verifica-se que a doutrina jurídica, com suporte em definições legais dos termos ambientais, ressalta uma hierarquia nas formas de reparação ambiental. O princípio da reparação ambiental, nesse entendimento, é gênero que comporta as seguintes espécies: restauração, recuperação, compensação e indenização.

Nessa sequência é que se deve priorizar a reparação ambiental quando da ocorrência do dano ambiental. Laudos técnicos periciais devem ficar incumbidos de orientar os aplicadores do Direito quanto à forma de reparação ambiental a ser aplicada para cada situação verificada quando danos ambientais vierem à tona.

Edis Milaré (2005, p. 830) aborda a questão, argumentando que:

O Brasil adotou a teoria da reparação integral do dano ambiental, o que significa que a lesão causada ao meio ambiente há de ser recuperada em sua integridade e qualquer norma jurídica que disponha 
em sentido contrário ou que pretenda limitar o montante indenizatório a um teto máximo será inconstitucional; por isso mesmo, quando não for possivel a reparação do dano, ainda será devida a indenização pecuniária correspondente, a ser revertida para os Fundos de Defesa dos Direitos Difusos, previstos no artigo 13 da Lei 7.347/85.

A indenização será tratada no tópico seguinte ao se dissertar sobre a fixação do quantum debeatur nas ações indenizatórias ambientais.

Quanto à compensação ambiental, é do magistério de Freitas (2011, p. 14) que "ao contrário das medidas de reparação in situ (restauração e recuperação), a compensação tem como fim a 'substituição' do bem ambiental afetado por equivalente, de modo que o equilíbrio ecológico seja restaurado”. A autora (2011, p. 14) disserta que

A compensação de que se trata aqui é justamente uma dessas formas de reparar o dano ambiental, através da qual se reconstitui ou melhora um outro bem ou sistema ambiental equivalente ao afetado. Deve ser permitida apenas nas hipóteses em que a reparação in natura e in situ (restauração e recuperação) for verdadeiramente impossivel (total ou parcialmente) ou como medida que precede a indenização (na reparação dos danos extrapatrimoniais, reparação dos danos interinos, p. ex.) (grifo da autora).

Pela definição fica patente que a compensação ambiental é uma ótima modalidade de reparação ambiental quando se verifica a irreversibilidade do dano ambiental. Esse tipo de reparação ambiental, a compensação ambiental, deve ser priorizada em detrimento da indenização na reparação dos danos extrapatrimoniais $^{1}$ e na reparação dos danos interinos ou intercorrentes. ${ }^{2}$

1 [...] o dano ambiental extrapatrimonial ou moral inclui apenas os interesses pessoais juridicamente tutelados, contudo a possibilidade de reparação deve estender-se aos danos extrapatrimoniais coletivos, passando a tutelar não só interesses na esfera individual, mas também uma conotação mais ampla. Pressupõe um direito de personalidade de caráter difuso, onde o traço marcante é a união indeterminada de sujeitos, com comunhão de interesses, onde o dano em questão atinge a coletividade de forma indiscriminada. (FREITAS, Flávia Gomes de. Dano ambiental extrapatrimonial - aspectos do tema. In: Âmbito Jurídico, Rio Grande, XII, n. 68, p. 1, set. 2009. Disponível em: <http://www.ambito-juridico.com.br/site/?n_link=revista_ artigos_leitura\&artigo_id=6733\&revista_caderno=5>. Acesso em: 04 mar. 2015).

2 E se a restauração integral do meio ambiente lesado, com a consequente reconstituição completa do equilíbrio ecológico, depender de lapso de tempo prolongado, necessário que se compense tal perda: é o chamado lucro cessante ambiental, também conhecido como dano interino ou intercorrente.

(FREITAS, Cristina Godoy de Araújo. Valoração do dano ambiental: algumas premissas. In: Revista do Ministério Público do Estado de Minas Gerais. Edição Especial Meio Ambiente: A Valoração de Serviços e Danos Ambientais, 2011, p. 10-17). 


\section{A fixação do quantum debeatur nas ações indenizatórias ambientais}

A indenização ou reparação pecuniária, como anteriormente mencionado, constitui uma das formas da reparação ambiental. Nas questões ambientais, essa forma de reparação ambiental é considerada subsidiária em relação às outras formas, ou seja, em relação à restauração, recuperação e compensação.

A indenização pecuniária ambiental deve ser aplicada sempre na impossibilidade da aplicação de uma das outras formas de reparação ambiental ou em consonância com uma delas, de maneira cumulativa, pelo fato da restauração (primeira modalidade da reparação ambiental a ser perseguida) não ser de fácil alcance.

É essa espécie de reparação ambiental - a restauração - a única compatível com o princípio da restitutio in integrum, genericamente considerado na responsabilidade civil, ou com o princípio da restituição ao status quo ante, de larga utilização na responsabilidade civil ambiental. Essa expressão - status quo ante - significa simplesmente reparar o equilíbrio ecológico desfeito.

A fixação do quantum debeatur - expressão em latim que significa o quanto se deve ou o quanto será pago - constitui tarefa de difícil estimativa para os peritos ambientais de diferentes disciplinas, bem como para os operadores do Direito. Os operadores do Direito são autorizados em lei para cobrarem indenizações por danos ambientais.

Com isso, a doutrina jurídica trabalha no sentido de estabelecer critérios, amparados em princípios jurídicos, que facilitem a tarefa delegada aos operadores do Direito.

Nesse caminhar, Sendim (1998, p. 177) leciona que a quantificação econômica do dano ambiental pode ser determinada de acordo com os critérios:

a) a análise da proporcionalidade das medidas de restauração natural; b) a compensação dos usos humanos durante o período de execução da restauração natural; c) a compensação dos danos ecológicos quando a restauração se revele - total ou parcialmente - impossivel ou desproporcional.

Gerent (2009, p. 12), ao dissertar sobre a liquidação de sentença condenatória por danos ambientais difusos, cita Wambier e Almeida (2007, p. 99). Esclarece a autora que "o objetivo da liquidação de sentença é um pronunciamento judicial que defina o quantum da obrigação genérica que foi objeto da sentença condenatória". Salienta ainda que, nesse procedimento jurídico, "a problemática está no procedimento para fixação do quantum debeatur. Apurar os valores dos 
bens e serviços ambientais é possível com a ajuda da teoria econômica neoclássica, com seus critérios e métodos para apurá-los. [...]".

[...] Dentre as formas de reparar o dano ambiental, contudo, a reparação pecuniária é a que carece de maior discussão e aperfeiçoamento jurídico-legal, tendo em vista que o Direito Ambiental não acompanhou o desenvolvimento da teoria econômica neoclássica quando esta trouxe critérios e métodos de valoração dos bens e serviços ambientais, principalmente no que se refere à liquidação das sentenças condenatórias.

Gerent (2009, p. 5) elucida que

O Decreto 4.339/02, que trata da Política Nacional da Biodiversidade, é a única norma jurídica que traz no inciso XIV do Anexo I a previsão de critérios para fixação do valor do dano ambiental ao estabelecer: "o valor de uso da biodiversidade é determinado pelos valores culturais e inclui valor de uso direto e indireto, de opção de uso futuro e, ainda, valor intrínseco, incluindo os valores ecológico, genético, social, econômico, científico, educacional, cultural, recreativo e estético".

O Ministério do Meio Ambiente, dos Recursos Hídricos e da Amazônia Legal, ao editar, juntamente com outras instituições, o Manual para Valoração Econômica de Recursos Ambientais, elaborado pelo professor Ronaldo Seroa da Motta, já definia os valores mencionados no Decreto no 4.339, de 22 de agosto de 2002 (Brasil, 2002), e estabelecia os métodos econômicos para suas estimativas.

Com isso, Motta (1998, p. 11-12) esclarece que

Primeiro devemos perceber que o valor econômico dos recursos ambientais é derivado de todos os seus atributos e, segundo, que estes atributos podem estar ou não associados a um uso. Ou seja, o consumo de um recurso ambiental se realiza via uso e não-uso. [...].

No caso de um recurso ambiental, os fluxos de bens e serviços ambientais, que são derivados do seu consumo, definem seus atributos.

Nas páginas já mencionadas Motta (1998) elucida mais os critérios sobre os valores que devem ser considerados ao se quantificar monetariamente os recursos ambientais e os danos que esses sofrem quando indevidamente explorados. Salienta o autor: 
Entretanto, existem também atributos de consumo associados à própria existência do recurso ambiental, independentemente do fluxo atual e futuro de bens e serviços apropriados na forma do seu uso.

Assim, é comum na literatura desagregar o valor econômico do recurso ambiental (VERA) em valor de uso (VU) e valor de não-uso (VNU).

Valores de uso podem ser, por sua vez, desagregados em: Valor de Uso Direto (VUD) - quando o indivíduo se utiliza atualmente de um recurso, por exemplo, na forma de extração, visitação ou outra atividade de produção ou consumo direto; Valor de Uso Indireto (VUI) - quando o benefício atual do recurso deriva-se das funções ecossistêmicas, como, por exemplo, a proteção do solo e a estabilidade climática decorrente da preservação das florestas; Valor de Opção (VO) - quando o indivíduo atribui valor em usos direto e indireto que poderão ser optados em futuro próximo e cuja preservação pode ser ameaçada. Por exemplo, o benefício advindo de fármacos desenvolvidos com base em propriedades medicinais ainda não descobertas de plantas em florestas tropicais. O valor de não-uso (ou valor passivo) representa o valor de existência (VE) que está dissociado do uso (embora represente consumo ambiental) e deriva-se de uma posição moral, cultural, ética ou altruística em relação aos direitos de existência de espécies não-humanas ou preservação de outras riquezas naturais, mesmo que estas não representem uso atual ou futuro para o indivíduo. Uma expressão simples deste valor é a grande atração da opinião pública para salvamento de baleias ou sua preservação em regiões remotas do planeta, onde a maioria das pessoas nunca visitarão ou terão qualquer benefício de uso.

[...]

Assim, uma expressão para VERA seria a seguinte: $V E R A=(V U D+$ $V U I+V O)+V E$ (grifos do autor).

Gerent (2009, p. 6-7), em análise sobre a expressão, apresentada por Seroa da Motta (1998, p. 11-12), mostra sua aplicação quanto aos aspectos material e extrapatrimonial do dano ambiental, conforme segue:

Assim, a avaliação de danos ambientais deve ser considerada sob dois aspectos, material e extrapatrimonial, aquele apresentando, então, a equação: valor patrimonial do ambiente $=$ valor de uso (direto ou indireto) + valor de opção; enquanto a apuração do valor do dano extrapatrimonial seguiria assim: valor não patrimonial do ambiente $=$ valor de existência. Acrescenta-se que o bem ambiental pode apresentar todos esses valores simultaneamente, uma vez que a natureza 
é complexa, o homem ainda não foi capaz de descobrir todas as utilidades e benefícios de todas as espécies e formas de vida não humanas.

Depois de informar que os métodos de valoração ambiental contemplados pelo manual são divididos em métodos da função de produção e métodos da função de demanda, funções essas características da economia neoclássica, Motta (1998, p. 13) aponta que a “[...] a adoção de cada método dependerá do objetivo da valoração, das hipóteses assumidas, da disponibilidade de dados e do conhecimento da dinâmica ecológica do objeto que está sendo valorado".

Nesse momento surge a necessidade do trabalho transdisciplinar entre 0 profissional do Direito e profissionais de outras disciplinas como a Biologia, a Economia, a Engenharia Florestal e outros que possam atuar como peritos na área ambiental para apurarem o quantum debeatur através do método de valoração ambiental que melhor captará e quantificará os efeitos danosos da conduta humana sobre o meio ambiente.

Como orientação para os peritos que atuam na área ambiental, a Associação Brasileira de Normas Técnicas (ABNT, 2008) elaborou e editou a norma técnica NBR 14653 - Parte 6, em consonância com o Manual para Valoração Econômica de Recursos Ambientais do Ministério do Meio Ambiente, bem como com o Decreto no 4.339/02, que trata da Política Nacional da Biodiversidade.

Essa norma diz respeito à avaliação econômica de recursos naturais. Dois objetivos vêm expressos na norma técnica: primeiro, detalhar os procedimentos gerais da norma de avaliação de bens [...] no que diz respeito à avaliação de recursos naturais e ambientais e, segundo, complementar os conceitos, métodos e procedimentos gerais para os serviços técnicos de avaliação de recursos naturais e ambientais. Além disso, a norma técnica NBR 14653 - Parte 6 fixa as diretrizes para a valoração de recursos ambientais quanto a:

a) classificação da sua natureza;

b) instituição de terminologia, definições, símbolos e abreviaturas;

c) descrição das atividades básicas;

d) definição da metodologia básica;

e) requisitos básicos de laudos e pareceres técnicos de avaliação.

Há de se observar que, embora a norma técnica saliente a avaliação econômica de recursos naturais e ambientais, essa norma é de ampla utilização na avaliação econômica dos danos ambientais que incidam sobre esses recursos.

Paulo de Bessa Antunes (2002, p. 40), ao dissertar sobre a avaliação econômica de recursos ambientais e, por consequência, sobre a avaliação econômica dos danos ambientais, salienta que 
[...] parte da constatação de que os recursos ambientais são escassos e que seu uso na produção e no consumo acarretam a sua redução e degradação. Ora, se o custo da redução dos recursos naturais não for considerado no sistema de preços, o mercado não será capaz de refletir a escassez. Em assim sendo, são necessárias políticas públicas capazes de eliminar a falha no mercado, de forma a assegurar que os preços dos produtos reflitam os custos ambientais.

A opinião de Paulo Afonso Leme Machado (2006, p. 66) quanto ao assunto não difere da opinião de Paulo de Bessa Antunes (2002), ainda que escrita em outras palavras:

O uso gratuito dos recursos naturais tem representado um enriquecimento ilegítimo do usuário, pois a comunidade que não usa do recurso ou que o utiliza em menor escala fica onerada. 0 poluidor que usa gratuitamente o meio ambiente para nele lançar poluentes invade a propriedade pessoal de todos os outros que não poluem, confiscando o direito de propriedade alheia.

Os órgãos ambientais têm adaptado os métodos trazidos pela norma técnica para avaliação econômica de danos ambientais, visando redução de tempo e de custos exigidos na aplicação desses métodos.

Alguns órgãos ambientais, para situações específicas, formulam métodos de avaliação econômica de danos ambientais que, depois de utilizados em seus laudos ou pareceres técnicos, são também utilizados pelo Poder Judiciário para a fixação do quantum debeatur em ações indenizatórias ambientais.

Esse é o caso, por exemplo, da posição adotada pelo juiz federal Ricardo de Castro Nascimento, da Justiça Federal - Seção São Paulo, da $1^{\text {a }}$ Vara Federal de Caraguatatuba, na Ação Civil Pública no 0006782-42.2011.403.6103, na qual figuram como autor o Ministério Público Federal e como ré a Petrobras Transportes S.A. - Transpetro.

Pelos danos ambientais extrapatrimoniais originados por derramamento de petróleo no mar pela ré, o magistrado sugere para a fixação do quantum debeatur a utilização do trabalho técnico desenvolvido pela Companhia de Tecnologia de Saneamento Ambiental (CETESB), ligada à Secretaria do Meio Ambiente do governo paulista. $\mathrm{O}$ trabalho técnico da CETESB constitui uma "Proposta de Critério para Valoração Monetária de Danos Causados por Derrames de Petróleo ou de seus Derivados no Ambiente Marinho".

Nos dizeres do juiz federal Ricardo de Castro Nascimento (2013, p. 14), 
O trabalho elaborado pela CETESB guarda a devida razoabilidade e proporcionalidade que devem nortear o julgador na fixação do quantum a ser indenizado, especialmente com as peculiaridades do caso presente.

[...] os critérios adotados no referido trabalho da CETESB foram utilizados na fixação mínima do dano ambiental a ser reparado em decisões do Egrégio Tribunal Regional Federal da 3르 Região em casos de derramamento de petróleo e seus derivados no litoral paulista.

Mirra (2004, p. 346), ao dissertar sobre a reparação pecuniária do dano ao meio ambiente, salienta que “[...] Em princípio subsidiária, ela tem sido, ainda assim, bastante utilizada na prática como mecanismo de compensação do prejuízo causado ao meio ambiente e seus elementos".

O autor menciona procedimentos e metodologias técnico-científicos adotados para a fixação do quantum debeatur nas ações indenizatórias ambientais e escreve que

[...], muitos são, de fato, os estudos desenvolvidos nos últimos anos no intuito de definir critérios aceitáveis que permitam quantificar o montante reparatório de danos ambientais. É importante compreender, contudo, que, mesmo amparada em avaliações científicas realizadas à luz da situação fática constatada por técnicos e peritos na matéria, a definição da quantia a ser paga pelo degradador na ação civil pública de responsabilidade civil por danos ao meio ambiente é acima de tudo questão de direito e não mera questão de fato (grifo do autor).

Por ser uma questão de direito, significa que o magistrado pode arbitrar o valor em pecúnia do dano ambiental, ou, em outras palavras, fixar o quantum debeatur nas ações indenizatórias ambientais.

Santos (2009, p. 17), ao dissertar sobre critérios para fixação da indenização por danos morais, salienta o que é perfeitamente aplicável na fixação da indenização nas ações ambientais ao serem tratados os danos extrapatrimoniais. Nos dizeres do autor

[...], o arbitramento do montante indenizatório pelo juiz não se confunde com arbitrariedade. Ao contrário, é uma atividade intelectual que se desenvolve com base nas circunstâncias do caso sub judice. Isso quer dizer que o juiz deve se louvar nos elementos constantes dos autos e, conforme o caso, na sua experiência de vida, para alcançar um valor que seja razoável para aquele caso (grifo do autor). 
Santos (2009, p. 17) prossegue em sua argumentação ao explicar que “como dito, não é dado ao juiz arbitrar livremente o valor da indenização. Ao contrário, deve o mesmo atentar para as circunstâncias do caso concreto, segundo critérios inteligíveis. [...]".

Retomando o exemplo anteriormente mencionado sobre a Ação Civil Pública no 0006782-42.2011.403.6103, na qual figuram como autor o Ministério Público Federal e como ré a Petrobras Transportes S.A. - Transpetro, versando sobre danos ambientais extrapatrimoniais originados por derramamento de petróleo no mar pela ré, o magistrado Ricardo de Castro Nascimento (2013, p. 14) sugere para a fixação do quantum debeatur a utilização do trabalho técnico desenvolvido pela CETESB - Companhia de Tecnologia de Saneamento Ambiental, ligada à Secretaria do Meio Ambiente do governo paulista, exatamente por perceber nesse trabalho técnico critérios ou parâmetros inteligiveis que permitem ao juiz que irá fixar o quantum debeatur perceber a extensão do dano ambiental e verificar se o montante estimado guarda uma relação razoável com o dano então ocorrido.

Nas palavras do magistrado

A quantificação do dano ambiental para fins de reparação deve levar em conta o volume de petróleo derramado, a vulnerabilidade da área atingida, a toxicidade do produto, a persistência do produto vazado no meio aquático. Tais parâmetros foram utilizados pela CETESB, empresa de reconhecida excelência em matéria ambiental, na elaboração do trabalho Proposta de Critério para Valoração Monetária de Danos Causados por Derrames de Petróleo ou de seus Derivados no Ambiente Marinho, disponível no site oficial da empresa ambiental paulista.

Rosa (2010, p. 166), por sua vez, argumenta que "a liquidação dos danos ambientais não é tarefa das mais fáceis de ser alcançada. A fixação do quantum debeatur deve ficar ao alvedrio do magistrado no curso da indenizatória, ação civil pública ou ação popular, que definirá o valor da indenização por arbitramento".

Rosa (2010, p. 166-167) cita Fiorillo e Abelha (2010, p. 102) e Miranda (2009, p. 245) e salienta que esses autores enumeram parâmetros ou critérios a serem verificados no caso concreto que auxiliam o julgador na fixação da indenização. A gravidade da perturbação (intensidade leve, moderada ou severa; tamanho da área afetada; duração da agressão; tempo de recuperação da área afetada), a condição econômica do poluidor e o grau de proveito obtido pelo ofensor são exemplos de parâmetros citados para serem observados pelo julgador.

Claro está que esses parâmetros ou critérios constituem a base da aplicação dos princípios da razoabilidade e da proporcionalidade no ato do julgamento, haja 
vista que a fixação do quantum debeatur nas ações indenizatórias ambientais não visa espoliar o agente poluidor, inviabilizando o seu empreendimento. 0 objetivo é responsabilizar o agente pelo dano ambiental causado e retirar da sociedade o ônus da degradação perpetrada sobre o meio ambiente.

Édis Milaré (2005, p. 829) esclarece o objetivo mencionado ao dissertar sobre o princípio da responsabilidade objetiva:

[...]. É o que, em outras palavras, diz a moderna doutrina: 'O princípio da responsabilidade objetiva é o da equidade, para que se imponha o dever de reparação do dano e não somente porque existe responsabilidade'. Assume o agente todos os riscos de sua atividade, pondo-se fim, em tese, à prática inadmissível da socialização do prejuízo e da privatização do lucro.

É nesse momento que saber sobre a existência dos métodos de avaliação econômica dos recursos ambientais deve fazer parte dos conhecimentos do julgador para acionar peritos que possam ajudá-lo na fixação do quantum debeatur. As estimativas econômicas do valor pecuniário do dano ambiental, juntamente com a aplicação dos parâmetros ou critérios que alicerçam os princípios da proporcionalidade e da razoabilidade, é que darão ao julgador a tranquilidade necessária para a fixação do quantum debeatur nas ações civis ambientais sem infringência ao princípio da justiça.

A justiça é, em última análise, o que se busca na tentativa de fazer prevalecer o desenvolvimento hodiernamente denominado sustentável.

Apesar de ser uma forma subsidiária ou secundária que compõe a reparação ambiental, a fixação do quantum debeatur ou a indenização nas ações ambientais não é menos exigente para o profissional do Direito e para os peritos que nelas trabalham do que qualquer outra das formas de reparação ambiental. Exige-se desses profissionais, nesse caso, a aplicação do método hermenêutico-sistêmico delineado por Barbosa e Nóbrega (2013, p. 179), que escrevem sobre o Direito Ambiental em perspectiva.

Esses autores descrevem o método hermenêutico-sistêmico com vistas a “interpretar e compreender os princípios da Política Nacional do Meio Ambiente - PNMA - contidos na Lei Federal no 6.938/81, a partir dos fundamentos (epistemológicos e jurídicos) ambientais construídos".

Quanto ao método hermenêutico-sistêmico, Barbosa e Nóbrega (2013, p. 182-183) lecionam que

Esse método permite interpretar e compreender os sentidos jurídicos das leis, dos decretos, das resoluções e entender as características 
implícitas dos documentos, das instituições e das entidades. Também lança seu foco para explicações científicas considerando aspectos sociais da realidade humana e ambiental, [...]. Informações jurídicas e não jurídicas relacionadas com o meio ambiente devem ser compreendidas e expostas.

A dimensão hermenêutica interpreta os textos jurídicos e os documentos não jurídicos, enquanto a dimensão sistêmica interliga as componentes jurídicas, sociais, econômicas, técnicas, filosóficas, éticas e ecológicas.

O que se espera, então, do julgador que fixa o quantum debeatur nas ações indenizatórias ambientais e dos profissionais de outras disciplinas que o auxiliam é atentarem para as nuances ou características do dano ambiental e para os métodos de estimativas do valor monetário desse dano. Essas condições exigem um trabalho transdisciplinar que envolve magistrados e técnicos ambientais de diversas disciplinas.

A transdisciplinaridade é uma característica da responsabilidade civil ambiental quando se trata da fixação do quantum debeatur nas ações indenizatórias ambientais, característica essa herdada do Direito Ambiental por ser componente relevante desta disciplina.

Nessa linha de raciocínio, Gerent (2009, p. 14) apela para a positivação legal dos critérios e métodos para valoração dos bens e serviços ambientais com o seguinte argumento:

Conclui-se, finalmente, que enquanto a legislação ambiental não positivar os critérios e métodos para valoração dos bens e serviços ambientais objeto de dano ambiental está-se diante de incertezas jurídicas e qualquer sentença condenatória ambiental não está adequada à tutela material do meio ambiente ecologicamente equilibrado exatamente pela ausência de técnicas/instrumentos processuais para liquidá-la.

Enquanto não se legisla sobre a matéria, como sugerido por Gerent (2009, p. 14), resta então ao Poder Judiciário agir tal qual o Ministério Público Federal e alguns Ministérios Públicos Estaduais que atuam extrajudicialmente na reparação indenizatória ambiental. Esses órgãos públicos se debruçam sobre a matéria através de cursos, seminários, debates, estudos e produção de material técnico sobre as metodologias já desenvolvidas para a fixação do quantum debeatur nesta temática. 
Nesse agir, há o envolvimento de promotores de justiça e de analistas ambientais de diversas instituições e de analistas ambientais dos próprios Ministérios Públicos, visando o aperfeiçoamento e a aplicação dessas metodologias nas mais diversas formas de ocorrência do dano ambiental.

\section{Conclusão}

De todo o exposto fica claro que a responsabilidade civil por danos ao meio ambiente tem como pressuposto básico a reparação do dano ambiental. Essa reparação, ainda que amplamente divulgada e sendo hoje um princípio constitucional, não consiste em tarefa trivial devido às características do dano ambiental e por ser a própria reparação ambiental dividida em diferentes formas de execução que carecem de estudos para serem aplicadas nas diferentes formas de ocorrências do dano ambiental.

Como anteriormente mencionado, a doutrina jurídica, com suporte em definições legais dos termos ambientais, ressalta uma hierarquia nas formas de reparação ambiental, colocando o princípio da reparação ambiental como gênero que comporta as seguintes espécies: restauração, recuperação, compensação e indenização. Nessa sequência é que se deve priorizar a reparação ambiental quando da ocorrência do dano ambiental.

A indenização, apesar de constar como espécie subsidiária do gênero reparação ambiental, é muito utilizada nas ações indenizatórias ambientais. Por isso, essa modalidade de reparação ambiental deve gozar da atenção dos aplicadores do Direito para surtir os efeitos esperados ao se tratar a responsabilidade civil daqueles que degradam o meio ambiente.

Por isso, ao se dissertar neste artigo sobre a fixação do quantum debeatur nas ações indenizatórias ambientais, espera-se assim contribuir para os aplicadores do Direito nessa seara que constitui tarefa motivo de incertezas jurídicas. As incertezas jurídicas prejudicam a consecução de um meio ambiente ecologicamente equilibrado como direito de todos.

O Poder Judiciário, apesar de todas as responsabilidades que hoje Ihe são impostas, e que acarretam um acúmulo considerável de serviços, não deve, por isso, fechar os olhos para a correta indenização quando surgem os danos ambientais. Os prejuízos que tal atitude pode acarretar para a sociedade são de difícil quantificação, dificuldade essa infinitamente maior que a delineada para a fixação do quantum debeatur nas ações civis indenizatórias ambientais. 


\section{Fixing the debeatur quantum in environmental compensation claims}

Abstract: This article aims to elaborate on fixing the quantum debeatur in environmental compensation claims, given the difficulties for law enforcers when it is necessary to use the compensation in the environmental remediation sphere, the principle of environmental law discipline which today enjoys constitutional status. The approach method used was the inductive through literature search, selecting and mentioning different doctrinal positions on the subject. There is legal uncertainty that permeates the matter. This legal uncertainty is the result of the characteristics of environmental damage and the various forms of environmental remediation that require transdisciplinary work among legal practitioners and professionals from other disciplines to make effective the right to an ecologically balanced environment.

Keywords: Environmental liability. Environmental damage. Environmental remediation. Environmental compensation.

Contents: $\mathbf{1}$ Introduction - $\mathbf{2}$ Civil liability for environmental damage - $\mathbf{3}$ Repair the environmental damage $\mathbf{-} \mathbf{4}$ Fixing the debeatur quantum in environmental compensation claims - $\mathbf{5}$ Conclusion - References

\section{Referências}

ANTUNES, Paulo de Bessa. Direito ambiental. 6. ed. Rio de Janeiro: Lumen Juris, 2002.

ASSOCIAÇÃO BRASILEIRA DE NORMAS TÉCNICAS. NBR 14653 - Parte 6: Avaliação de bens - Parte 6: Recursos naturais e ambientais. Fixa diretrizes para a valoração de recursos naturais e ambientais, em vigor a partir de 30 jun. 2008. Rio de Janeiro, 2008.

BARBOSA, Erivaldo Moreira; NÓBREGA, Maria de Fátima. O Direito Ambiental em Perspectiva: da hermenêutica-sistêmica ao saber ambiental. Revista Veredas do Direito, Belo Horizonte, v. 10, n. 20, p. 179-205, jul./dez. 2013.

CAVALIERI FILHO, Sergio. Programa de responsabilidade civil. 4. ed. São Paulo: Malheiros, 2008.

BRASIL. Constituição (1988). Constituição da República Federativa do Brasil. Disponível em: <http://www.planalto.gov.br/ccivil_03/Constituicao/Constituiçao.htm>. Acesso em: 14 fev. 2015.

BRASIL. Poder Judiciário de São Paulo. Ação Civil Pública no 0006782-42.2011.403.6103. Justiça Federal- 1a Vara Federal de Caraguatatuba: agosto de 2013. [19 p]. Disponivel em: <http://www.jfsp.jus.br/assets/Uploads/administrativo/NUCS/ decisoes/2013/130911transpetro.pdf>. Acesso em: 02 abr. 2015.

BRASIL. Decreto no 4339, de 22 de agosto de 2002. Disponível em: <http://www. planalto. gov.br/ccivil_03/decreto/2002/d4339.htm>. Acesso em: 14 mar. 2015.

BRASIL. Lei no 6938, de 31 de agosto de 1981. Brasília, DF: Senado Federal, 1981. Disponível em: <http://www.planalto.gov.br/ccivil_03/leis/I6938.htm>. Acesso em: 14 fev. 2015.

BRASIL. Lei no 9985, de 18 de julho de 2000. Brasília, DF: Senado Federal, 2000. Disponível em: <http://www.planalto.gov.br/ccivil_03/leis/19985.htm>. Acesso em: 22 fev. 2015. 
BRASIL. Poder Judiciário de São Paulo. Ação Civil Pública no 0006782-42.2011.403.6103. Justiça Federal - 1 $^{\text {a }}$ Vara Federal de Caraguatatuba: agosto de 2013. [19 p]. Disponivel em: <http://www.jfsp.jus.br/assets/Uploads/administrativo/NUCS/decisoes/2013/130 911transpetro.pdf>. Acesso em: 02 abr. 2015.

CARDIN, Valéria Silva Galdino; BARBOSA, Haroldo Camargo. Formas de reparação do dano ambiental. Revista de Ciências Jurídicas - UEM, v. 6, n. 2, jul./dez. 2008, p. 159. Disponível em: <www.periodicos.uem.br/ojs/index.php/RevCiencJurid/article/.../5900>. Acesso em: 18 mar. 2015.

CUSTÓDIO, Helita Barreira. Responsabilidade civil por danos ao meio ambiente. Tese (Concurso de livre docência). São Paulo, Departamento de Direito Civil - Faculdade de Direito, Universidade de São Paulo, 1983.

FIORILLO, Celso Antônio Pacheco; ABELHA, Rodrigues Marcelo. Manual de direito ambiental e legislação aplicável. 2. ed. São Paulo: Max Limonad, 1999.

FREITAS, Cristina Godoy de Araújo. Valoração do dano ambiental: algumas premissas. In: Revista do Ministério Público do Estado de Minas Gerais. Edição Especial Meio Ambiente: a valoração de serviços e danos ambientais, 2011, p. 10-17.

FREITAS, Flávia Gomes de. Dano ambiental extrapatrimonial - aspectos do tema. In: Âmbito Jurídico, Rio Grande, XII, n. 68, set. 2009. Disponível em: <http://www.ambito-juridico.com. $\mathrm{br} / \mathrm{site} / ? \mathrm{n}$ _link=revista_artigos_leitura\&artigo_id=6733\&revista_caderno=5>. Acesso em: 04 mar. 2015.

FREITAS, Vladimir Passos de. Direito administrativo e meio ambiente. 3. ed. Curitiba: Juruá, 2001.

GERENT, Juliana. Liquidação de sentença condenatória por danos ambientais difusos. Processos Coletivos, Porto Alegre, v. 1, n. 1, out. 2009. Disponível em: <http://www. processoscoletivos. net/doutrina/18-volume-1-numero-1-trimestre-01-10-2009-a-31-122009/73-liquidacao-de-sentenca-condenatoria-por-danos-ambientais-difusos ->. Acesso em: 24 mar. 2015.

WAMBIER, Luiz Rodrigues; ALMEIDA, Flávio Renato Correia de; TALAMINI, Eduardo. Curso avançado de processo civil, v. 2; Processo de execução. 9. ed. São Paulo: Revista dos Tribunais, 2007.

LEITE, José Rubens Morato; AYALA, Patrick de Araújo. Dano ambiental: do individual ao coletivo extrapatrimonial: teoria e prática. 4. ed. atual. e ampl. São Paulo: Revista dos Tribunais, 2011, 416 p.

LOPES, Samuel Henderson Pereira. O instituto da responsabilidade civil no Código Civil de 2002. In: Âmbito Jurídico, Rio Grande, XIV, n. 87, abr. 2011. Disponível em: <http://www. ambito-juridico.com.br/site/?n_link=revista_artigos_leitura\&artigo_id=9125>. Acesso em: mar. 2015.

MACHADO, Paulo Affonso Leme. Direito ambiental brasileiro. 14. ed. São Paulo: Malheiros, 2006.

MILARÉ, Edis. Direito do ambiente: doutrina, prática, jurisprudência e glossário. São Paulo: Revista dos Tribunais, 2005. 1119 p. 
MIRANDA, Marcos Paulo de Souza. Configurações e indenizações de danos morais coletivos decorrentes de lesão a bens integrantes do patrimônio cultural brasileiro. In: Revista de Direito Ambiental, São Paulo, RT, ano 14, abr./jun. 2009.

MIRRA, Álvaro Luiz Valery. Ação civil pública e a reparação do dano ao meio ambiente. 2. ed. atual. São Paulo: Editora Juarez de Oliveira, 2004, 448 p.

MOTTA, R. S. Manual para valoração econômica de recursos ambientais. Brasília, DF: Ministério do Meio Ambiente, dos Recursos Hídricos e da Amazônica Legal, 1998. 218 p.

REALE, Miguel. Lições preliminares de Direito. 25. ed. 2001, p. 371. Disponível em: <http:// aprender.ead.unb.br/pluginfile.php/40071/mod_resource/content/1/Livro\%20Miguel\%20 Reale>. Acesso em: 06 jul. 2016.

RODRIGUES, Silvio. Direito Civil. Volume IV, 19. ed. São Paulo: Saraiva. 2002.

ROSA, Mardióli Dalla. Dano ambiental ocasionado pela exploração desenfreada dos recursos naturais. Revista Veredas do Direito, Belo Horizonte, v. 7, n. 13/14, p. 157-172, jan./dez. 2010. Disponível em: <http://domhelder.edu.br/revista/index.php/veredas>. Acesso em: 18 abr. 2015.

SANTOS, Romualdo Baptista dos. Critérios para fixação da indenização por dano moral. Texto para o XXXV Congresso Nacional de Procuradores do Estado - Ceará, 2009. Disponível em: <http://www. procuradoria.al.gov.br/centro-de-estudos/teses/xxxv-congresso-nacional-deprocuradores-de-estado/direito-civil/CRITERIOS\%2OPA>. Acesso em: 18 abr. 2015.

SENDIM, José de Souza Cunhal. Responsabilidade civil por danos ecológicos: da reparação do dano através da restauração natural. Coimbra: Coimbra, 1998.

SILVA, De Plácido e. Vocabulário Jurídico. Rio de Janeiro: Forense, 1982.

Recebido em: 17.06 .2015

Pareceres: 16.09.2015 e 29.03.2016

Aprovado em: 12.07.2016

Informação bibliográfica deste texto, conforme a NBR 6023:2002 da Associação Brasileira de Normas Técnicas (ABNT):

REZENDE, Elcio Nacur; CUNHA, Nivaldo Caetano da. A fixação do quantum debeatur nas ações indenizatórias ambientais. Direitos Fundamentais \& Justiça, Belo Horizonte, ano 10, n. 34, p. 91-114, jan./jun. 2016. 